\title{
20
}

\section{EL CONSENSO DE LA OCDE SOBRE CRÉDITOS A LA EXPORTACIÓN CON APOYO OFICIAL. Marco actual, evolución y desafíos}

El Consenso OCDE es el marco de gobernanza internacional para la financiación oficial a la exportación, surgido del «pacto entre caballeros» alcanzado en 1976 en el seno del G6, en un contexto de competencia agresiva, con el propósito de dotarse de reglas objetivas a favor de una competencia basada en la calidad de los bienes y servicios en lugar de en los términos de la financiación ofrecida, para preservar un terreno de juego equilibrado, level playing field, y reducir las distorsiones sobre el comercio internacional. Desde los años ochenta ha existido un continuo proceso de desarrollo y adaptación del acuerdo. No obstante, el Consenso hace frente en la actualidad a una creciente pérdida de influencia y representatividad, con un peso relevante de la actividad de países no participantes o de prácticas desarrolladas al margen de este. El contexto de polarización y fragmentación actual dificulta la coordinación, y la creciente agresividad de la competencia podría implicar de nuevo una carrera a la baja con efectos negativos sobre el comercio internacional. Frente a un nuevo periodo de incertidumbre, el reciente lanzamiento de trabajos para un proceso de modernización del Consenso es un paso positivo, pero será necesario un elevado grado de compromiso político y el impulso de nuevas iniciativas de coordinación a favor de un marco de gobernanza verdaderamente global.

Palabras clave: comercio internacional, crédito a la exportación, financiación internacional, apoyo oficial. Clasificación JEL: F13, F34, F36, G15.

\section{Introducción}

El Acuerdo sobre Directrices en Materia de Créditos a la Exportación con Apoyo Oficial de la Organización de Cooperación y Desarrollo Económicos (OCDE) —denominado comúnmente

\footnotetext{
* Técnico Comercial y Economista del Estado. Subdirector General Adjunto de Fomento Financiero de la Internacionalización. Dirección General de Comercio Internacional e Inversiones.

Ministerio de Industria, Comercio y Turismo.

Versión de enero de 2021.

DOI: https:/doi.org/10.32796/bice.2021.3132.7150
}

como el Consenso (de la OCDE) — es el marco de gobernanza internacional que recoge las reglas sobre la financiación oficial a la exportación. Se trata de un acuerdo internacional aprobado en 1978 en el seno de la OCDE — sobre la base del Consenso alcanzado en 1976 por los miembros del G6 - con el fin de establecer un marco para el uso ordenado de créditos a la exportación ${ }^{1}$ a medio y largo plazo, fomentando $D$

1 Crédito comprador y suministrador. 
condiciones igualitarias frente a la competencia desleal.

El Consenso regula la financiación con apoyo oficial, con un periodo de reembolso de dos o más años, ligada a la formalización de contratos de exportación de bienes y servicios ${ }^{2}$ (con la excepción de productos agrarios y equipamiento militar). Las reglas aplican a la financiación directa ${ }^{3}$, al seguro o garantías de crédito ${ }^{4} \mathrm{y}$ al ajuste de tipos de interés ${ }^{5}$ de carácter oficial. Asimismo, el acuerdo se asienta sobre mecanismos de intercambio de información, incluyendo los términos de las transacciones individuales ${ }^{6}$, para garantizar un adecuado seguimiento y transparencia.

Por otra parte, si bien el Consenso se impulsó en el marco de la OCDE - y recibe el apoyo administrativo de su Secretaría-, se trata de un acuerdo independiente. El acuerdo es un «pacto entre caballeros", no vinculante, dependiendo su aplicación de la buena voluntad de las partes. No obstante, este es de obligado cumplimiento para los Estados miembros (EE MM) de la Unión Europea (UE), ya que se encuentra recogido en el ordenamiento jurídico comunitario (Reglamento (UE) 1233/2011 del Parlamento Europeo y del Consejo).

Los participantes del Consenso son la UE y la mayor parte de países miembros de la OCDE (Tabla 1). En todo caso, el acuerdo tiene una vocación multilateral respecto de la eventual participación de otros países -miembros o no de la OCDE-, y diferentes países asisten a reuniones de los participantes como invitados/ observadores.

\footnotetext{
2 No aplica a la financiación de la inversión exterior.

3 Incluyendo refinanciaciones.

4 Cobertura (pure cover) ofrecida por el Estado, o por cuenta de este, sobre crédito bancario, facilitando así su concesión.

5 Convenios de ajuste recíproco de intereses (interest make-up agreements), facilitando el crédito bancario a tipo fijo.

6 Notificaciones ex ante y ex post, en función del tipo de financiación
} y características de la operación.
TABLA 1

PRINCIPALES PAÍSES/BLOQUES COMERCIALESY SU PARTICIPACIÓN EN EL CONSENSO DE LA OCDE

\begin{tabular}{|c|c|c|}
\hline Países & OCDE & Consenso OCDE \\
\hline EE MM de la UE 27 & Sí1 & $\mathrm{sí}^{2}$ \\
\hline Reino Unido & sí & sí3 \\
\hline Noruega & sí & sí \\
\hline Suiza & sí & sí \\
\hline Estados Unidos & sí & sí \\
\hline Canadá & sí & sí \\
\hline Japón & sí & sí \\
\hline Corea del Sur.... & sí & $\mathrm{sí}^{4}$ \\
\hline Australia & sí & sí \\
\hline Nueva Zelanda .............. & sí & sí \\
\hline Turquía & sí & sí ${ }^{5}$ \\
\hline Israel ........... & sí & NO \\
\hline México $^{7}$ & sí & NO \\
\hline Brasil ......... & NO & $\mathrm{NO}^{6}$ \\
\hline Rusia & NO & NO \\
\hline India & NO & NO \\
\hline China & NO & NO \\
\hline Sudáfrica & NO & NO \\
\hline \multicolumn{3}{|c|}{$\begin{array}{l}121 \text { EE MM de la UE27 son miembros de la OCDE. La Comisión } \\
\text { Europea participa asimismo en las reuniones. }\end{array}$} \\
\hline \multicolumn{3}{|c|}{$\begin{array}{l}{ }^{2} \text { La UE interviene en las reuniones de participantes del Consenso } \\
\text { con una voz, coordinando su posición, a través de la Comisión. } \\
\text { El Consenso se encuentra recogido en el acervo comunitario y es } \\
\text { vinculante para todos los EE MM. }\end{array}$} \\
\hline \multicolumn{3}{|c|}{${ }^{3}$ En proceso de formalización de su participación, tras su salida de la UE. } \\
\hline \multicolumn{3}{|c|}{${ }^{4}$ Participante del Consenso desde 1997.} \\
\hline \multicolumn{3}{|c|}{5 Participante del Consenso desde 2018.} \\
\hline \multicolumn{3}{|c|}{$\begin{array}{l}6 \text { No participante del Consenso, pero sí del Acuerdo Sectorial sobre } \\
\text { Aeronaves Civiles (ASU) desde } 2007 \text {. }\end{array}$} \\
\hline \multicolumn{3}{|c|}{$\begin{array}{l}7 \text { Otros países de la OCDE no participantes del Consenso son Islan- } \\
\text { dia, Chile, Colombia y Costa Rica. }\end{array}$} \\
\hline Fuente: elaboración propia. & & \\
\hline
\end{tabular}

\section{Origen del Consenso de la OCDE}

El origen del acuerdo se remonta a la década de los años setenta, asociado a la voluntad de los Gobiernos del G6 de alcanzar un acuerdo para poner orden en la financiación oficial de exportaciones y limitar la competencia financiera entre los Estados, en el contexto de inestabilidad y desequilibrios tras la caída del sistema de Bretton-Woods, que había dado paso a un periodo de tensiones comerciales y subvenciones, con efectos externos distorsionantes. $\quad \square$ 
Décadas atrás, la creación de la Unión de Berna (UB, Asociación Internacional de Aseguradoras de Inversión y Crédito a la Exportación, públicas y privadas) en $1934^{7}$ había supuesto la primera iniciativa de cooperación internacional el respecto.

Desde finales de los años cincuenta la competencia en materia de financiación oficial entre Estados Unidos y algunos países europeos -reaccionando, en parte, a la creciente capacidad competitiva norteamericana en sus antiguos mercados de influencia- condujo a demandas para que la UB impulsara un marco de disciplinas -que, no obstante, carecía de jurisdicción o capacidad al respecto-. En los años sesenta, el asunto de la competencia en la financiación oficial se incorporó al Grupo de Trabajo del GATT (Acuerdo General sobre Aranceles Aduaneros y Comercio) sobre subvenciones a la exportación, buscando la eliminación de los créditos subsidiados, por considerarse un tipo de «subsidio directo» (ámbito que el GATT planteaba restringir, salvo en productos primarios), sin que tales propuestas tuvieran respuesta a nivel internacional. No sería hasta 1963 cuando la OCDE decidió ampliar su alcance incluyendo el ámbito de la financiación oficial y su competencia (Moravcsik, 1989).

En 1964 se creó el Grupo de Crédito y Garantías de Crédito a la Exportación (ECG) de la OCDE para el impulso de disciplinas y recomendaciones. Si bien estas tuvieron alcance limitado — sin que llegaran a ratificarse algunos de los preacuerdos alcanzados-, sí se lograron avances en materia de notificación de transacciones y procedimiento de consultas.

7 Fundada en 1934 por tres aseguradoras privadas (España, Francia e Italia) y una pública (Reino Unido) como foro de intercambio de información. La UB cuenta en la actualidad con 83 miembros (entidades públicas y privadas).
El shock del petróleo de 1973 generó elevados déficits, apostándose por la financiación a la exportación subsidiada como vía para reducir los déficits, aunque las subidas de tipos implicaron un gravoso aumento del coste de la subsidiación en una carrera a la baja por la creciente competencia (Levit, 2004).

En 1973 se dio un paso importante con el impulso por parte de Estados Unidos de reuniones de coordinación del G5 —en los márgenes de la junta anual del Fondo Monetario Internacional (FMI)-, en favor de una regulación, ante los temores de que la creciente inestabilidad condujera a una guerra comercial. Los esfuerzos continuaron en los años siguientes en el marco de las reuniones del FMI, OCDE, G5 y G6 ${ }^{8}$ —cerrándose entre 1974 y 1975 acuerdos stand-still sectoriales para limitar los términos y subsidios a los niveles entonces existentes (Moravcsik, 1989)-.

Finalmente, en 1976 el G6 alcanzó un consenso relativo a disciplinas sobre crédito oficial a la exportación, que dio lugar al acuerdo aprobado en febrero de 1978 por una veintena de países (el bloque de nueve EE MM de la Comunidad Económica Europea, otros siete países europeos -incluido España-, Australia, Canadá, Estados Unidos y Japón, adhiriéndose Austria y Nueva Zelanda ese mismo año).

En las décadas posteriores se fueron acordando sucesivas modificaciones, revisiones y ampliaciones de los términos del Consenso, incluyendo entendimientos sectoriales.

\section{Justificación de la regulación}

Los instrumentos de apoyo financiero oficial a la exportación, ya sean concedidos $\triangleright$

8 En paralelo a las negociaciones de la Ronda Tokyo del GATT. 
directamente por un Gobierno o Estado, o a través de una entidad o agencia de crédito a la exportación (ECA) actuando por cuenta de este, se dirigen a facilitar la financiación a compradores extranjeros para la formalización de operaciones y proyectos desarrollados por exportadores nacionales, contribuyendo así a impulsar su internacionalización y las exportaciones.

El uso de la financiación oficial a la exportación es una práctica habitual en los países desarrollados y en cada vez más países de renta media. Su objetivo primordial es reforzar la competitividad de la oferta de bienes y servicios nacionales en los mercados internacionales, acompañándola de una financiación atractiva, para el adecuado posicionamiento $y$ avance de las exportaciones nacionales que contribuya a la creación de riqueza y empleo en el país de origen. Al mismo tiempo, se pretende evitar que la oferta nacional se vea adversamente seleccionada frente a una oferta extranjera de menor calidad que cuente con un apoyo financiero oficial atractivo.

Por otra parte, la existencia de imperfecciones y fallos de mercado ${ }^{9}$ justifica la actuación del sector público frente a situaciones de restricción del crédito —o su encarecimiento prohibitivo- que impida o limite la concesión de financiación hacia determinados agentes, mercados y sectores. Este sería el caso de las pequeñas y medianas empresas exportadoras - pymes(de menor tamaño, capacidad de diversificación e historial de crédito, con operaciones de menor volumen y financiación requerida), en desventaja frente a exportadores de mayor tamaño. Así mismo, el desarrollo de proyectos en determinados países emergentes puede encontrar dificultades para obtener financiación sostenible,

9 Externalidades, problemas informacionales, agentes con poder de mercado. dado el mayor riesgo asociado a pesar de la rentabilidad potencial. Finalmente, pueden existir sectores de interés por sus externalidades positivas (energías renovables, transporte sostenible, gestión de agua y residuos, lucha contra el cambio climático) para los que el coste de la financiación no recoge adecuadamente sus beneficios potenciales, justificando la actuación del sector público frente a tales imperfecciones.

Existen, por tanto, argumentos a favor de la concesión de financiación oficial a la exportación. En todo caso, es necesario asegurar unas reglas ortodoxas sobre los términos financieros, con principios sólidos y buenas prácticas, evitando que la financiación oficial sea un mero mecanismo de subvención o ayuda con efectos distorsionantes sobre el comercio internacional. Es deseable, por tanto, un marco de gobernanza ortodoxo, transparente y flexible — para su adecuación al entorno económico global-, que favorezca todo lo posible un terreno de juego equilibrado y no distorsionante, siendo este el objetivo de las reglas del Consenso OCDE.

En este sentido, el crédito a la exportación con apoyo oficial ofrecido dentro de las reglas del Consenso es considerado como una excepción a las prohibiciones recogidas en el Acuerdo de la Organización Mundial del Comercio (OMC) sobre Subvenciones y Medidas Compensatorias, teniendo esta financiación oficial un carácter eminentemente contracíclico, con un papel más activo en los periodos de mayor restricción y encarecimiento del crédito en mercado.

\section{Marco actual}

\subsection{Marco actual del Consenso de la OCDE}

El Consenso consta del cuerpo general del acuerdo y una serie de anexos, como $\square$ 
TABLA 2

ANEXOS DEL CONSENSO RELATIVOS A ENTENDIMIENTOS SECTORIALESY DE PROJECT FINANCE

\begin{tabular}{|c|c|c|c|}
\hline Anexo & Año & Acuerdo & Cuestiones diferenciadas (entre otras) \\
\hline I. SSU .. & 2005 & Buques $\ldots$ & Amortización (hasta 12 años), pago anticip, esquema repago \\
\hline II. NSU & 2009 & Plantas nucleares . & Amortización (hasta 18 años), cálculo de CIRR \\
\hline III. ASU . & 2007 & Aeronaves civiles ${ }^{1}$ & Amortización (hasta 15 años), cálculo de CIRR, primas \\
\hline IV. CCSU & 2014 & Energ. renov., cambio climático y agua ....... & $\begin{array}{l}\text { Amortización (hasta } 18 \text { años}^{2} \text { ), gasto local, cálculo de CIRR, } \\
\text { Acuerdo en revisión }\end{array}$ \\
\hline V. RSU. & 2014 & Infraestructura ferroviaria & Amortización (hasta 12/14 años²), límites sindicación, CIRR \\
\hline VI. CFSU. & 2015 & Centrales termoeléctricas de carbón ............... & $\begin{array}{l}\text { Amortización (hasta 10/12 años }{ }^{2} \text { ), restricciones de } \\
\text { elegibilidad }^{3}, \text { Acuerdo en revisión }^{4}\end{array}$ \\
\hline VII. PF ..................... & 2015 & 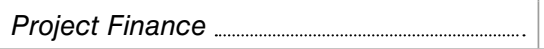 & Amortización (hasta 14 años), esquema de repago, CIRR \\
\hline \multicolumn{4}{|c|}{$\begin{array}{l}{ }^{1} \text { Acuerdo autónomo. Funcionamiento independiente sin recurrir al Acuerdo General (con la participación de Brasil, no firmante del Consenso). } \\
2 \text { Diferente según el sector y categoría de proyecto (CCSU), categoría del país (RSU), tipo de planta (CFSU). } \\
{ }^{3} \text { Plantas subcríticas menos eficientes (solo en países menos avanzados). } \\
{ }^{4} \text { CFSU en proceso de revisión, con propuestas para poner fin a la elegibilidad del sector. } \\
\text { Fuente: OCDE v elaboración propia. }\end{array}$} \\
\hline
\end{tabular}

resultado de las sucesivas revisiones (Tabla 2). El cuerpo general incluye las disposiciones generales, reglas de financiación en términos comerciales, financiación concesional y procedimientos relativos a diferentes cuestiones (notificaciones, consultas, matching de ofertas de terceros, excepciones temporales -o common lines- y mecanismos de revisión), complementado a su vez por el bloque de anexos ${ }^{10}$.

\section{Reglas para la concesión de créditos}

El Consenso regula los términos y condiciones relativos a la concesión de créditos con apoyo oficial, siendo elegible, en principio, cualquier tipo de exportación. Es decir, se puede ofrecer financiación en términos comerciales con apoyo oficial a compradores - públicos o privados- de cualquier país de destino y, a priori $^{11}$, cualquier proyecto de exportación.

10 Los anexos recogen los entendimientos o acuerdos sectoriales, compromisos de notificación, metodología del cálculo de primas, categorías de riesgo y mecanismos de mitigación, definiciones y la metodología de cálculo de los tipos CIRR (commercial interest reference rate).

11 Con limitaciones específicas recogidas en los anexos sectoriales.
El límite al importe máximo del contrato comercial elegible para recibir apoyo oficial se fija sobre la base del valor de los bienes y servicios exportados ${ }^{12}$ (export contract value) dentro del contrato comercial en su conjunto. El importe financiable será como máximo del $85 \%$ del valor de los bienes y servicios exportados, más el valor del gasto local ${ }^{13}$ en el país de destino hasta un importe máximo equivalente al $30 \%$ del valor de los bienes y servicios exportados (estando previsto que el límite del gasto local aumente en los próximos meses hasta el $40 \%$ y $50 \%$, en función de la categoría del país de destino ${ }^{14}$ ). Asimismo, el importe de la prima de riesgo asociada al crédito podrá ser financiado/asegurado, pasando su valor, en su caso, a formar parte del importe del crédito comercial.

Por tanto, el Consenso no establece umbrales respecto del reparto entre contenido nacional o extranjero, que adicionalmente podrán $\triangle$

\footnotetext{
12 Bienes y servicios nacionales y de tercer país, incluyendo transporte y fletes.

13 Gastos asociados a bienes y servicios suministrados por el país de destino, necesarios para completar el proyecto.

14 Acuerdo en proceso de ratificación por parte de la UE.
} 
fijar los respectivos Estados en línea con su política de impulso de exportaciones.

Por su parte, el comprador extranjero deberá hacer frente a un pago anticipado (down payment) mínimo equivalente al $15 \%$ del valor de los bienes y servicios exportados ${ }^{15}$.

Asimismo, el Consenso limita el periodo máximo de amortización del crédito. La regla general (diferente de las aplicadas en los anexos sectoriales) establece plazos máximos de repago según el país beneficiario: 8,5 años ${ }^{16}$ en los países de categoría I (países OCDE de renta alta) y 10 años en los de categoría II (resto de países). En todo caso, el periodo de amortización no debe superar la vida útil de los bienes o equipos.

Por su parte, también se precisa el punto de arranque del crédito ${ }^{17}$ —descartando así periodos de gracia-, según la naturaleza de los bienes o servicios objeto de exportación (coincidiendo con la fecha de entrega o embarque ${ }^{18}$, en el caso de suministros, y con la firma del acta de entrega provisional, en el caso de proyectos llave en mano). Adicionalmente, el reembolso del crédito seguirá un esquema de repago que, con carácter general ${ }^{19}$, cuente con plazos iguales y regulares y con una frecuencia al menos semestral y una primera amortización no más tarde de seis meses tras el punto de arranque del crédito.

La regulación de volúmenes y plazos se acompaña de términos sobre tipos de interés y

\footnotetext{
15 A afrontar con recursos propios o financiado mediante un crédito complementario sin apoyo oficial.

16 Requiriéndose una notificación ex ante del crédito al resto de participantes; en caso contrario, el plazo será de 5 años.

17 Tras el periodo de ejecución del contrato $-\mathrm{y}$ de desembolso del crédito-, en que únicamente hay pago de intereses.

18 Pudiendo utilizarse medias ponderadas en el caso de varias entregas/embarques.

19 Previendo excepciones, previa notificación justificada, acotándose el nivel máximo de pagos individuales ( $25 \%$ del principal) y el máximo de vida media del crédito (WAL, periodo de tiempo hasta el repago de la mitad del principal).
}

prima asociada al riesgo de crédito, evitando subvenciones encubiertas, distorsiones y competencia desleal entre participantes.

El Consenso permite conceder financiación con apoyo oficial en cualquier divisa y tanto a tipo de interés fijo como variable, si bien el acuerdo no presenta disposiciones relativas al cálculo de tipos variables ${ }^{20}$, recogiendo, en todo caso, el objetivo de un eventual desarrollo futuro de reglas al respecto.

Por su parte, la financiación a tipo de interés fijo —enfoque más tradicional— está sujeta a la aplicación, como mínimo, del tipo CIRR (tipo fijo de interés comercial de referencia, por sus siglas en inglés), publicado mensualmente ${ }^{21}$. El tipo CIRR, para cada divisa, se calcula a partir de la rentabilidad del bono del Tesoro a un plazo de referencia apropiado - dentro de un rango máximo- según la operación, más un margen adicional ${ }^{22}$, estando prevista en los próximos meses la actualización de la metodología del cálculo del $\mathrm{CIRR}^{23}$, para su aplicación tras un periodo transitorio de dos años.

Asimismo, existen disposiciones relativas al cálculo de la prima de riesgo, asociada al riesgo de crédito asumido por el apoyo oficial (tomado directamente por el Estado en la financiación directa, o cubierto por este, en el caso del seguro de crédito oficial), con el objetivo $D$

20 Salvo en el caso del anexo sectorial de aeronaves civiles, indicándose que el tipo variable no podrá ser inferior al tipo de interés interbancario de la divisa correspondiente más un margen basado en datos históricos de las transacciones.

21 Tipos CIRR actuales para transacciones estándar (no incluidas en anexos sectoriales con marco de tipos diferenciado): https://www.oecd. org/trade/topics/export-credits/documents/cirrs.pdf

22 Método de cálculo hasta 2023: sistema con tres escalones de rentabilidad del bono del Tesoro (a 3, 5 o 7 años; para periodos de amortización de entre 3 y 5 años; entre más de 5 y 8,5 años; o más de 8,5 años, respectivamente), más un margen fijo de 100 puntos básicos (pb).

23 Método previsto a partir de 2023: sistema con granularidad frente al marco de tres escalones (plazos), mayor alcance de la horquilla (de 3 a 10 años), con un plazo de referencia que incluya el periodo de desembolso junto con la vida media del crédito, y una dinamización parcial y acotada del margen, de acuerdo a la información publicada de la reforma. Acuerdo en proceso de ratificación por parte de la UE. 
de incorporar un coste razonable, repercutido al acreditado/deudor.

Las primas de riesgo mínimas se calculan a partir de diferentes elementos: el grupo de riesgo del país de destino/deudor (según la Clasificación de Riesgo por Países) ${ }^{24}$, el horizonte de riesgo (equivalente al periodo de amortización más la mitad del periodo de desembolso), la categoría de riesgo del comprador/deudor, el porcentaje de cobertura de riesgo político y comercial, y los factores mitigantes del riesgo.

En el caso de la financiación directa, el tipo de interés deberá incrementarse en la prima de riesgo equivalente calculada en puntos porcentuales.

\section{Anexos sectoriales}

Desde la década de 1980, el Acuerdo General del Consenso se ha ido ampliando con diferentes entendimientos sectoriales (SU, por sus siglas en inglés), que recogen en anexos cuestiones o disciplinas específicas por sus necesidades o características especiales. En la actualidad existen seis entendimientos sectoriales y un anexo relativo a transacciones bajo esquemas de Project Ffinance ${ }^{25}$ (Tabla 2).

\section{Financiación concesional ligada}

El acuerdo recoge, asimismo, reglas relativas a la financiación concesional de carácter ligado. Se trata de una financiación concedida

\footnotetext{
24 Desarrollada en 1997, con revisiones periódicas de los países y categoría de riesgo.

Existen ocho grupos de riego: el grupo 0 (para países desarrollados) y los grupos 1 al 7 (de menor a mayor riesgo de impago).

https://www.oecd.org/trade/topics/export-credits/documents/cre-crccurrent-english.pdf

Existe un marco de primas mínimas para países de grupo 1 a grupo 7 y, desde 2016, un marco de primas para países con disponibilidad de mercado financiero privado de referencia (market benchmark countries).

25 Crédito a la exportación financiando a la sociedad de proyecto, con garantía de proyecto (frente a garantías soberana o corporativa).
}

en términos más favorables que los del merca$\mathrm{do}^{26}$ (con flexibilidades respecto del periodo de amortización, de gracia, tipo de interés o esquema de repago), condicionada a contratos de exportación (tied aid). El crédito otorgado llevará asociado, por tanto, un componente de donación o ayuda implícito denominado grado o elemento de concesionalidad (EC).

La concesionalidad (expresada en porcentaje) se calcula como la diferencia entre el valor nominal $(V N)$ y el valor actual neto de la financiación (VAN), respecto de su VN. Por su parte, el VAN se calcula mediante el descuento de los sucesivos flujos de caja utilizando como tasa de descuento el llamado $D D R$ (tipo de descuento diferenciado, con cuatro posibilidades según el periodo de repago) ${ }^{27}$.

$$
E C(\%)=\frac{V N-V A N}{V N} \text { donde VAN }=\sum_{n=1}^{t} \frac{F C_{t}}{(1+D D R)^{t}}
$$

Así, los términos de la financiación (periodo de amortización, de gracia, tipo de interés y esquema de repagos) influirán en los flujos del proyecto y en el EC (mayor cuanto más elevado sea el periodo de amortización/gracia y menor el tipo de interés cargado).

Así, la financiación concesional ligada puede tener, a priori, un importante componente de contribución al desarrollo - junto al impulso de exportaciones-, permitiéndose su concesión con ausencia de límites respecto de sus términos financieros (pago anticipado, punto de arranque, periodos de amortización y gracia, apoyo financiero máximo), pudiendo $\triangleright$

26 Pudiendo llegar a tener la consideración de Ayuda Oficial al Desarrollo (AOD), dado su carácter concesional.

27 Los DDR para cada divisa, revisados anualmente (cada 15 de enero), se calculan a partir de la media de los CIRR del último semestre más un margen (de entre 75 y 125 puntos básicos, en función del periodo de repago): https://www.oecd.org/trade/topics/export-credits/documents/ ddr-tad.pdf 
alcanzar el $100 \%$ del valor del contrato comercial.

Las reglas incluyen, eso sí, un EC mínimo ${ }^{28}$ del $35 \%$ y criterios de elegibilidad de países y proyectos. El marco actual —desde la reforma del Paquete de Helsinki de 1991- establece que solo serán elegibles para financiación concesional ligada los países con una categoría de renta media-baja ${ }^{29}$ o inferior a esta (según la lista que el Banco Mundial actualiza anualmente) $)^{30}$, y los proyectos considerados no comercialmente viables, en caso de financiarse en términos comerciales ${ }^{31}$ (en general, de sanidad, educación, infraestructuras, medio ambiente, servicios públicos y zonas rurales).

La denominada financiación concesional ligada «de tipo Helsinki» responde a los señalados criterios de renta del país y de no viabilidad comercial. No obstante, el acuerdo también prevé excepciones en tres casos: cuando el EC sea superior al $80 \%$ (en que podrá concederse a cualquier país y proyecto), cuando la financiación sea inferior a dos millones de DEG (derechos especiales de giro) - de minimis - (en que podrá concederse a cualquier tipo de proyecto) o cuando el país de destino pertenezca a la categoría de los países menos adelantados PMA $^{32}$ (en que podrá concederse a cualquier tipo de proyecto, si bien con un EC mínimo del $50 \%$ ).

\footnotetext{
28 Como excepción, se prevé la posibilidad de estar exento del cumplimiento del porcentaje mínimo de $E C$, en el caso de que la donación implícita no supere el $3 \%$ del valor total de la operación o el millón de DEG.

29 Renta per capita inferior a 4.045 USD en 2019.

30 Un país dejará de ser elegible cuando se encuentre en la categoría de países de renta media, o superior, durante dos años consecutivos.

31 La viabilidad económica de los proyectos se determina sobre la base de dos test: capacidad de generación de caja para cubrir costes operativos y de capital, y dificultad de obtención de financiación en mercado o en condiciones de mercado. La Ex Ante Guidance de la OCDE recoge pautas a título orientativo basadas en la experiencia acumulada.

32 Clasificación desarrollada por el Comité de Desarrollo de NN UU —actualizada cada tres años - relativa a países de renta baja (renta per cápita inferior a los 1.036 dólares en 2019) que hacen frente a debilidades estructurales para lograr un desarrollo sostenible.
}

Cabe mencionar que, si bien el Consenso no recoge reglas relativas a la financiación concesional no ligada o desligada, sí incluye requisitos de notificación al respecto, cuando se trata de operaciones con fines comerciales, para mayor transparencia ${ }^{33}$, junto a las disciplinas de notificación y consultas de créditos a la exportación con apoyo oficial.

\section{Otras consideraciones}

El acuerdo recoge adicionalmente la posibilidad teórica de los participantes de igualación (matching) de ofertas financieras conocidas ofrecidas por terceros -participante o no-, con el objetivo de lograr un escenario más equitativo (mediante un procedimiento de matching, previa notificación del caso y evidencia obtenida ${ }^{34}$ ).

Finalmente, el texto recoge la posibilidad de plantear excepciones o suspensiones temporales -common lines - sobre contenidos del acuerdo, o sobre transacciones específicas, debidamente justificadas.

\subsection{Recomendaciones adicionales al Consenso}

El marco de gobernanza se completa con un marco de buenas prácticas, a partir del conjunto de recomendaciones del Consejo de la OCDE, aprobadas a propuesta del Grupo de Trabajo sobre Créditos a la Exportación y Garantías de Crédito (ECG), que los países se comprometen de buena fe a dar cumplimiento:

\footnotetext{
33 Transparencia reforzada con la publicación anual del llamado Informe Helsinki, a partir del Acuerdo de Transparencia sobre Créditos de Financiación Desligada de 2004 (en vigor desde 2005), inspirado en las recomendaciones del DAC y demandas de participantes.

34 Con una reducida aplicabilidad por la complejidad de los requisitos y pruebas necesarias.
} 
- La Recomendación del Consejo sobre enfoques comunes en materia de financiación oficial a la exportación y medidas de diligencia debida (due diligence) social y medioambiental (Recomendación relativa a los common approaches en áreas medioambiental y social).

- Recomendación del Consejo relativa a prácticas de soborno en materia de financiación oficial a la exportación (Recomendación relativa a la lucha contra la corrupción).

- Recomendación del Consejo relativa a prácticas crediticias sostenibles en materia de financiación oficial a la exportación (Recomendación relativa a principios de financiación sostenible).

La Recomendación relativa a los common approaches recoge requisitos en el ámbito social y ambiental de los proyectos con apoyo financiero oficial a medio y largo plazo (evaluación de impacto, cumplimiento de estándares internacionales, medidas de compensación, transparencia y reportes anuales), así como el fomento de la toma de conciencia respecto de los principios de las Líneas Directrices de la OCDE para empresas multinacionales (a favor de una conducta empresarial responsable). El objetivo es garantizar prácticas comunes coherentes con los objetivos de desarrollo sostenible. El texto inicial se aprobó en 2003 (relativa al ámbito medioambiental), ampliándose en 2007 (ámbito social), 2012 (mayor alcance) y 2016 (refuerzo e informes de seguimiento anual).

Como resultado de la evaluación de su impacto potencial a nivel social y ambiental ${ }^{35}$, las

\footnotetext{
35 Las exportaciones de bienes o servicios que se destinen a proyectos ya existentes que no supongan cambios relevantes en su capacidad o funcionamiento no estarán sujetas a clasificación, revisión, evaluación ni difusión de información.
}

operaciones se clasifican en tres categorías: de impacto mayor (A), intermedio (B) o mínimo (C) - con requisitos a nivel de informes de evaluación, difusión de información, medidas de mitigación-. Los proyectos de categorías A y B deberán someterse a revisiones específicas de cara a asegurar el cumplimiento de estándares del país de destino, las normas de medio ambiente, salud y seguridad del Banco Mundial (EHS Guidelines), los indicadores de desempeño de la Corporación Financiera Internacional (IFC Peformance Standards), estándares de la UE, así como el cumplimiento de estándares sectoriales específicos. Podrán requerirse medidas de mitigación y compensación, y el apoyo financiero podrá ser denegado en caso de no alcanzarse estándares mínimos.

La Recomendación relativa a la lucha contra la corrupción supone, por su parte, la adaptación del Convenio de la OCDE para Combatir la Corrupción de Agentes Públicos Extranjeros en las Transacciones Económicas Internacionales en el ámbito del crédito a la exportación con apoyo oficial. El texto inicial es del año 2000 , habiendo sido revisado y ampliado en 2006 y 2019. Su objetivo es el impulso de medidas efectivas de concienciación, prevención y lucha contra sobornos y prácticas de corrupción en la actuación de agentes públicos, con restricciones relativas al pago de comisiones comerciales y medidas de transparencia.

Finalmente, la Recomendación relativa a principios de financiación sostenible en materia de financiación a la exportación con apoyo oficial pretende impulsar prácticas crediticias sostenibles con una financiación ortodoxa por parte de los participantes del Consenso -respetando límites de endeudamiento comercial establecidos por las instituciones multilaterales-, compatibles con políticas $\triangleright$ 
de endeudamiento sostenible en los países deudores.

El texto fue aprobado en 2018 — con base en guías y principios internacionales de ejercicios previos-y es el resultado de la colaboración del Grupo de Trabajo ECG de la OCDE con el Banco Mundial y el FMI, para contribuir a que los países beneficiarios de la financiación alcancen objetivos de desarrollo sostenible, previniendo eventuales problemas de endeudamiento insostenible.

Adicionalmente, la Recomendación del Comité de Ayuda al Desarrollo (CAD) de la OCDE, relativa a la desvinculación de la $A O D^{36}$, invita a sus miembros a desvincular su financiación oficial bilateral al desarrollo dirigida a los países de menor renta (PMA, HIPC ${ }^{37}$ y resto de países de renta baja). La recomendación fue publicada inicialmente en 1998 con referencia a los países PMA, extendiéndose a países HIPC y resto de países de renta baja, en 2004 y 2014, respectivamente. Los países miembros del CAD se comprometen al cumplimiento de la recomendación en la mayor medida posible.

\section{Evolución del Consenso y del crédito a la exportación con apoyo oficial}

El nacimiento y los primeros años del Consenso tuvieron lugar, como se ha señalado, en un contexto de inestabilidad, desequilibrios y tensiones comerciales.

El compromiso pretendía limitar la agresiva competencia y eventuales guerras comerciales,

\footnotetext{
36 La financiación concesional ligada — sujeta al Consenso- puede tener o no la consideración de AOD.

37 HIPC o PPAE (países pobres altamente endeudados): países de renta baja beneficiarios de iniciativas multilaterales de condonación de deuda (HIPC 1996, HIPC II 1999 e Iniciativa Multilateral de Alivio de la Deuda -IMAD/MDRI-2004).
}

poniendo orden en el crédito oficial a la exportación. El acuerdo de 1978 suponía reconciliar los objetivos de diferentes participantes de, por un lado, limitar los plazos de la financiación (dados los amplios plazos de créditos concedidos hasta entonces por EE UU) y, por otro, limitar la subsidiación de tipos (ampliamente utilizada entonces, que EE UU planteaba restringir), combinándose una regulación de precios y cantidades de la financiación oficial junto a cuestiones de intercambio de información, logrando un clima de mayor estabilidad ${ }^{38}$. El acuerdo inicial establecía requisitos de pago anticipado y una matriz — con tres categorías de países de destino- con periodos máximos de amortización y tipos de interés mínimos ${ }^{39}$. Los tipos de interés mínimos, fijados en términos nominales independientes de la moneda de la financiación, no eliminaban la subsidiación de tipos e introducían distorsiones entre monedas, penalizando a los países de menores tipos, con una ausencia inicial de revisión de sus niveles y una homogeneidad a la baja, que redundó en un marco inicial contraproducente en un contexto de subida de tipos de mercado de finales de los setenta (Moravcsik, 1989).

Por otra parte, la nueva regulación introducida en 1978 supuso el abuso de fórmulas de financiación concesional ligada como vía de escape, que aumentaron sensiblemente en los años posteriores.

Desarrollo de disciplinas desde los años ochenta

En 1983 tuvo lugar la primera modificación del Consenso, revisando el sistema de tipos $\triangleright$

\footnotetext{
38 Con el acuerdo stand-still para el sector de aeronaves civiles reflejado mediante common line.

39 Aplicables solo a financiación directa, escapando de la regulación los créditos con cobertura oficial (Moravcsik, 1989).
} 
mínimos (incrementándose ${ }^{40}$ e introduciendo diferencias con el desarrollo de tipos CIRR para las divisas de menores tipos) y exigiendo al menos un EC del $20 \%$ en la concesión de financiación concesional ligada (ampliándose hasta el $25 \%$ en 1985), lo que supuso un avance significativo. A continuación se alcanzaron igualmente entendimientos específicos para los sectores de plantas nucleares y aeronaves civiles, de especial sensibilidad, tras un periodo de abierta confrontación transatlántica.

Poco después llegaría la aprobación de la primera gran reforma del Consenso, con el llamado Paquete Wàllen de 1987 (Tabla 3), que incluía la construcción de tipos CIRR para cada divisa ${ }^{41}$ (para su aplicación sistemática en los países de categoría I, pudiendo aplicarse en otras divisas en caso de ser inferiores a los tipos mínimos de la matriz) (Vía Ozalla et al., 1993), la prohibición de financiación subsidiada en países industrializados y el aumento del EC mínimo al 35\% (a cambio de la adopción de los $D D R$ para su cálculo, frente a la tasa de descuento del $10 \%$ previamente existente ${ }^{42}$, considerada entonces reducida frente a tipos de interés más elevados en algunos participantes).

Con la aplicación del Consenso y el refuerzo de sus disciplinas como verdadero marco de gobernanza, unido a medidas de austeridad de algunos participantes, a mediados de la década de 1980 se había producido una moderación de los flujos de financiación oficial.

El nuevo marco de gobernanza se beneficiaba del clima de mayor cooperación, del

40 Pasando los tipos recogidos en la tabla/matriz del $7-8 \%$ al $10-12 \%$.

41 Cuyo cálculo se había aprobado en 1986.

42 El FMI y el Grupo del Banco Mundial continuaron usando una tasa de descuento del $10 \%$ para calcular el elemento de liberalidad o donación, que pasó a ser del 5\% a partir del año 2013. tamaño limitado del grupo y del elevado compromiso político con el Consenso por parte de los principales países participantes, acordando la Comunidad Económica Europea (CEE) la integración de las disciplinas del acuerdo en el acervo comunitario desde 1978. Las reuniones del Grupo de Participantes se han caracterizado en términos generales, desde entonces, por un ambiente de camaradería y cordialidad entre sus miembros —reguladores del marco internacional y al mismo tiempo regulados, fortaleciéndose en general los compromisos asumidos (Levit, 2004) — que ha favorecido el desarrollo de las negociaciones y la facilitación de consensos.

\section{Avances en los años noventa}

En la primera parte de los noventa, y frente a la moderación anterior, el volumen de créditos con apoyo oficial experimentó una fuerte expansión, con cifras que en 1995 habían triplicado a las de 1988 (Kuhn et al., 1995) (Gráfico 1). Por su parte, la financiación concesional ligada, considerada potencialmente distorsionante, suponía a principios de los noventa más de la quinta parte del apoyo financiero oficial de los participantes (destacando el peso mayoritario de Japón, seguido de varios países europeos). El alza del EC hasta el 35\% (si bien con tasas de descuento superiores desde 1987 tras el uso de los $D D R$ ) no había reducido la oferta de la financiación concesional ligada, viéndose con preocupación por algunos participantes, que demandaban un marco más ortodoxo y restrictivo al respecto.

En 1992 se dio un paso fundamental con la aprobación del llamado Paquete Helsinki, reforzando las disciplinas para esta financiación concesional ligada y estableciendo la no elegibilidad de países de renta media-alta y de $\triangle$ 
TABLA 3

EVOLUCIÓN DEL CONSENSO DE LA OCDE DESDE SU APROBACIÓN EN 1978

\begin{tabular}{|c|c|c|}
\hline Fecha & Hito & Descripción \\
\hline 1978 & Acuerdo General .... & Aprobación del Consenso OCDE en materia de crédito a la exportación con apoyo oficial. \\
\hline 1983 & Reforma de tipos & $\begin{array}{l}\text { Revisión de tipos mínimos e introducción de tipos CIRR para divisas de tipos reducidos. } \\
\text { Financ. concesional ligada sujeta a un EC del } 20 \% \text {. }\end{array}$ \\
\hline 1985 & Revisión de fin. concesional ... & $\begin{array}{l}\text { Aumento del elemento del } E C \text { mínimo del } 20 \% \text { al } 25 \% \text {, requisitos de notificación ex ante } \\
\text { y posibilidad de consultas entre participantes. }\end{array}$ \\
\hline 1984 & Anexo NSU .. & Aprobación del Acuerdo Sectorial sobre Plantas Nucleares (NSU), revisado en 2009. \\
\hline 1886 & Anexo CASU .... & Aprobación de un Acuerdo Sectorial sobre Aeronaves Civiles (ASU). \\
\hline 1987 & Paquete Wàllen .......... & $\begin{array}{l}\text { Construcción de CIRR para cada divisa y en fin. concesional, aumento del EC mínimo al } \\
35 \%(50 \% \text { en PMA) y uso de } D D R \text { para calcular el } E C \text {. }\end{array}$ \\
\hline 1992 & Paquete Helsinki ..... & $\begin{array}{l}\text { Revisión CIRR (margen } 100 \mathrm{pb} \text { todas divisas), no elegibilidad de fin. concesional países } \\
\text { renta media-alta y req. de no viabilidad comercial. }\end{array}$ \\
\hline 1994 & Paquete Schaerer ... & Generalización de tipos CIRR, simplificación de categorías de países, revisión de $D D R$. \\
\hline 1997 & Paquete Knaepen .... & $\begin{array}{l}\text { Acuerdo de primas basado en riesgo, costes y pérdidas potenciales. Desarrollo de } \\
\text { metodología de análisis y clasificación de riesgo país. }\end{array}$ \\
\hline 1998 & Anexo PF . & $\begin{array}{l}\text { Aprobación de términos para Project Finance -PF- (incorporados como anexo desde } \\
2003 \text {, con carácter permantente desde 2005). }\end{array}$ \\
\hline 2002 & Anexo SSU .... & Aprobación del Acuerdo Sectorial sobre Buques (SSU). \\
\hline 2005 & Anexo RESU .... & $\begin{array}{l}\text { Aprobacion del Acuerdo Sectorial sobre Energías Renovables y Agua (RESU), con } \\
\text { carácter permantente desde } 2009 \text { y ampliado en } 2012 .\end{array}$ \\
\hline 2007 & Anexo ASU. & $\begin{array}{l}\text { Aprobación del Acuerdo sobre Aeronaves Civiles (ASU) —en sustitución del CASU— } \\
\text { como un acuerdo independiente (revisado en 2011). }\end{array}$ \\
\hline 2007 & Revisión GL. & $\begin{array}{l}\text { Aumento del gasto local (GL) elegible del } 15 \% \text { al } 30 \% \text { del valor de los bienes y servicios } \\
\text { exportados. Permanente desde } 2011 .\end{array}$ \\
\hline 2010 & Paquete Malzkuhn-Drysdale ... & Actualización y mejora del sistema de primas para crédito comprador. \\
\hline 2012 & Anexo CCSU ..... & $\begin{array}{l}\text { Aprobación del Acuerdo Sectorial sobre Energías Renovables, Cambio Climático y Agua } \\
\text { (CCSU) en sustitución del RESU (ampliado en 2014). }\end{array}$ \\
\hline 2013 & Anexo RSU ... & $\begin{array}{l}\text { Aprobación de términos para el sector de FF CC (RSU). Inicialmente como common line } \\
\text { temporal y como anexo sectorial desde } 2014 \text {. }\end{array}$ \\
\hline 2015 & Anexo CFSU .... & Aprobación de términos para el sector de carbón (CFSU), como anexo sectorial desde 2016. \\
\hline 2016 & Revisión de primas & $\begin{array}{l}\text { Acuerdo de primas para países con disponibilidad de mercado financiero privado de } \\
\text { referencia (market benchmark countries). }\end{array}$ \\
\hline 2020(E) & Actualización GL y CIRR .......... & $\begin{array}{l}\text { Revisión de la metodología de cálculo del CIRR y aumento del gasto local máximo } \\
\text { elegible al } 40 \% / 50 \% \text {. Ratificación prevista en } 2021 .\end{array}$ \\
\hline
\end{tabular}

proyectos comercialmente viables (financiación de tipo Helsinki), con la excepción de financiación en términos muy concesionales (EC superior al $80 \%$ ), de minimis o hacia países PMA, en que los proyectos estarían exentos de requisitos de viabilidad comercial. La aplicación del Paquete Helsinki redujo significativamente la oferta de financiación concesional ligada respecto de cifras previas (contrayéndose cerca del $70 \%$ en 1993 y situándose en un $50 \%$ de media en las dos décadas posteriores). Tal reducción supuso que la financiación en términos comerciales pasara de suponer menos del $80 \%$ a estar en torno al $90-95 \%$. No obstante, también contribuyó a generar mayor volumen de financiación concesional desligada $^{43}$, no sujeta a Consenso (Gráfico 2 ). $\triangleright$

43 Con un peso mayoritario de Japón, seguido de Alemania y Francia. 


\section{EL CONSENSO DE LA OCDE SOBRE CRÉDITOS A LA EXPORTACIÓN CON APOYO OFICIAL...}
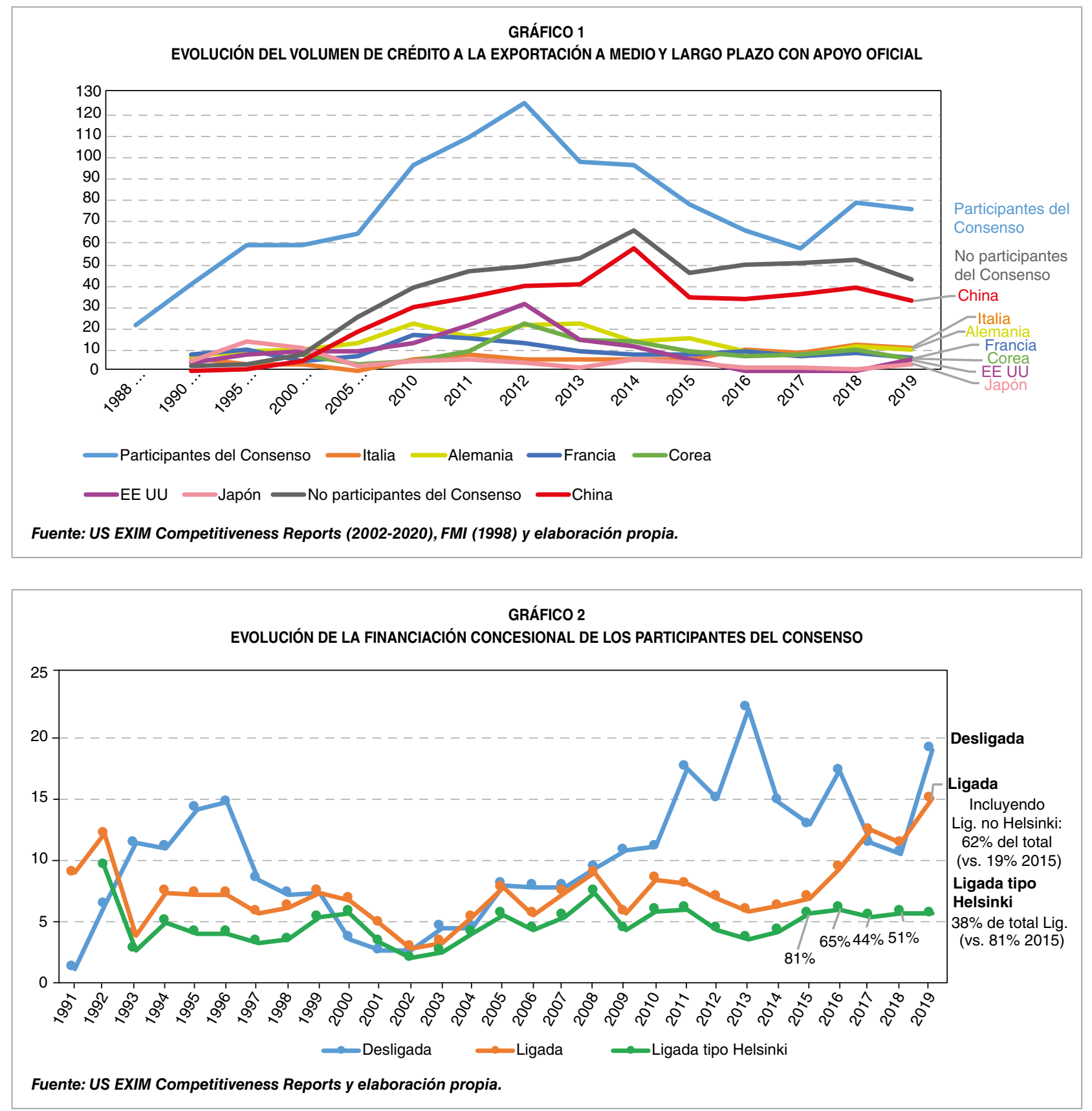

Su potencial efecto distorsionante y la constatación de abusos impulsaron demandas -especialmente por parte de EE UU-para su regulación ${ }^{44}$, con una fuerte oposición japonesa, y de algunos países europeos, que impidieron alcanzar acuerdos (siendo la base, en todo caso,

44 Con consultas y quejas de EE UU frente a la financiación japonesa —de facto- ligada (US EXIM Bank, 2002-2004). del acuerdo de 2004 de transparencia reforzada que afloraría un mayor volumen ${ }^{45}$ ).

En 1994 tiene lugar la aprobación del llamado Paquete Schaeren, que simplifica los términos del acuerdo con la generalización de tipos CIRR y las categorías de países.

45 Acuerdo de transparencia sobre créditos de financiación desligada (2004). 
Por otra parte, en 1995 tuvo lugar la creación de la OMC tras las negociaciones de la Ronda de Uruguay (1986-1994), aprobándose, entre otros, el previamente señalado Acuerdo sobre Subvenciones y Medidas Compensatorias (ASMC), que actualizaba las disciplinas existentes contra subvenciones distorsionantes $^{46}$. Si bien el ASMC prohíbe las subvenciones en el comercio internacional (incluyendo potencialmente la concesión de créditos a la exportación), el crédito con apoyo oficial ofrecido en los términos del Consenso se encuentra expresamente excluido, no considerándose como subvención por lo que respecta a la OMC. Esta cláusula, de carácter vinculante, ofrece confort a los participantes frente a eventuales cuestionamientos (safe harbor), pudiendo a priori reforzar su compromiso con el Consenso.

A pesar de su relativa debilidad, el ASMC (safe harbor) sería el principal elemento legal de disuasión frente a prácticas distorsionantes (Dawar, 2020).

En todo caso, se consideraba deseable desarrollar un marco de primas mínimas basadas en un análisis ortodoxo de riesgos - con principios de mercado- que mejorara los términos del acuerdo y reforzara el safe harbor ofrecido por el ASMC. En este sentido, en 1997 tiene lugar la aprobación del llamado Paquete Knaepen, entrando en vigor en 1999 (Tabla 3).

\section{Consolidación y actualización}

En la segunda parte de la década de los noventa y primeros años del nuevo milenio tiene lugar un periodo de consolidación con variaciones dentro de una relativa estabilidad. A pesar de las crisis asiática y rusa, los mercados

\footnotetext{
46 Código de subvenciones del GATT de 1979.
}

emergentes reciben una parte significativa y creciente del crédito oficial, de en torno a tres cuartas partes del total -muy concentrada en los principales destinos ${ }^{47}$-, con una significativa reducción de la concesión de financiación hacia países HIPC y en general de renta baja (que en 1995 habían llegado a recibir el 15\% del total) (Wang et al., 2005).

Una vez aprobado en 1997 el marco de primas, metodología de análisis y categorías de riesgo, entre 1998 y 2007 tiene lugar un periodo de consolidación del Consenso y su actualización con la incorporación de sucesivos anexos sectoriales, con términos específicos adaptados (Project Finance, buques y energías renovables) y transformación del Acuerdo de Aeronaves Civiles (ASU) en otro independiente tras la adhesión de Brasil en 2007 (no participante del Consenso). Asimismo, en 2007 tiene lugar la aprobación del aumento del límite máximo de gasto local elegible para apoyo oficial, pasando del $15 \%$ al $30 \%$ del valor de los bienes y servicios exportados, inicialmente prevista para un periodo de prueba de tres años y que pasa a ser permanente desde 2011. En efecto, existían demandas a favor de la posibilidad de mayor gasto local en destino (especialmente importante en los proyectos de mayor envergadura, volumen y financiación) ligado habitualmente a costes de instalación y construcción, ejecutados en ocasiones por filiales o socios de la empresa exportadora.

\section{Reorganización del panorama internacional}

Desde mediados de la década de los noventa, en un entorno de mayor desarrollo financiero y liquidez, se produce un $\triangleright$

47 En mercados como China, Rusia, Brasil, México, Nigeria o Indonesia. 
aumento progresivo de la actividad de aseguradoras privadas, especialmente en el negocio de corto plazo. También participan en mayor medida en el negocio de medio y largo plazo, en un contexto de innovación financiera y mayor flexibilidad. Asimismo, existe un aumento de la capacidad crediticia de la banca local en los países emergentes y aumenta la financiación comercial de instituciones financieras internacionales y bancos regionales de desarrollo.

Paralelamente, se produce una retirada de las ECA del negocio de corto plazo. En el caso de la UE, la Comisión Europea publicó en 1997 su Comunicación sobre cobertura de riesgo de crédito a corto plazo (CE, 1997), instando a los EE MM a poner fin a su actividad de apoyo financiero por cuenta del Estado en el caso de riesgos comercializables (riesgos a corto plazo en mercados desarrollados, dada la capacidad de cobertura del sector privado). Respecto del negocio de medio y largo plazo, tras la entrada en vigor en 1999 de las reglas sobre primas, reduciéndose la capacidad de subsidiación de riesgos - con un menor efecto desplazamiento del sector privado-, las ECA mantienen su objetivo prioritario de impulso de las exportaciones, pero con un mayor enfoque en su papel de hacer frente a fallos de mercado, cubrir gaps de financiación y, a priori, participar en proyectos de mayor riesgo (por su mayor capacidad de recobro, diversificación y actuación como financiador o garante de último recurso) ${ }^{48}$, si bien manteniendo en algunos casos estándares conservadores en la asunción de riesgos. Por su parte, la financiación oficial hacia los sectores específicos, como buques y aeronaves civiles, sí mantiene su carácter

48 En el caso del US EXIM Bank, con una política explícita de no competencia con el sector privado. clave, dados los volúmenes y riesgos singulares de las transacciones ${ }^{49}$.

Asimismo, desde finales de los noventa y principios del nuevo siglo existe mayor relevancia de países no participantes del Consenso, mayoritariamente China e India. Si bien China ha ofrecido financiación oficial en el exterior desde la segunda parte del siglo xx (Horn et al., 2019), en 1995 su concesión de crédito a la exportación era inferior a 1.000 millones, destacando en aquel momento como receptor de este tipo de flujos. Pero desde entonces su crédito oficial a la exportación ha mostrado un avance robusto. En el caso de China, las entidades EXIM Bank of China y SINOSURE, fundadas en 1994 y 2001, respectivamente, han registrado un crecimiento exponencial desde sus inicios, con una financiación conjunta de 9.000 millones de dólares en 2003, 18.500 millones en 2005 y más de 30.000 millones en 201050. En menor medida, el crédito oficial de India también ha mostrado avances notables desde finales de los noventa.

\section{Crisis financiera internacional y papel contracíclico de la financiación oficial}

En los años previos a la crisis, el crédito a la exportación sujeto al Consenso mantuvo un avance moderado, con una dinámica ligada a la evolución de financiación a buques y aeronaves. Tras el estallido de la crisis (y sus efectos en términos de restricción financiera, crisis económica desde 2008 y mayor aversión al riesgo), aumenta el recurso al apoyo financiero oficial en sus diferentes fórmulas (incluida la $D$

\footnotetext{
49 Más de un $30 \%$ a principios del nuevo siglo, llegando a suponer el $50 \%$ del crédito oficial durante los años de la crisis, reduciendo su peso posteriormente por la caída de operaciones bajo el ASU.

50 Wang et al. (2005) y US EXIM Bank $(2008,2014)$. Excluyendo otra financiación desligada y financiación a inversiones.
} 
cobertura del riesgo de ejecución de avales). Dado su papel contracíclico, el volumen de crédito con apoyo oficial creció substancialmente, alcanzando máximos históricos desde 2010, reduciéndose a partir de $2013^{51}$ y registrando en 2017 niveles previos al estallido de la crisis $(\text { Gráfico } 1)^{52}$.

La posterior reducción de la financiación oficial coincide con una mayor participación de aseguradoras privadas en el crédito a la exportación ${ }^{53}$ — vía seguro y reaseguro- y una especial atención de las ECA hacia pymes, con un apoyo reforzado dada su mayor vulnerabilidad y capacidad potencial. En este periodo se aprueba la actualización del sistema de primas, nuevos entendimientos en sectores de infraestructuras (CCSU, RSU, CFSU) y la revisión del régimen de primas para transacciones en que existan referencias de mercado (Tabla 3). Y, más recientemente, se produce la revisión al alza del límite de gasto local al $40 / 50 \%$ y la actualización de la metodología de cálculo del CIRR (ambas en proceso de ratificación).

\section{Transformación del escenario internacional}

La financiación oficial sujeta a las reglas del Consenso ha ido perdiendo terreno progresivamente a lo largo de la última década, representando actualmente en torno a un tercio de la

\footnotetext{
51 Con cifras de crédito a la exportación de los participantes influidas por la reducida actividad del US EXIM Bank entre 2015 y 2019. En junio de 2015 expiró su autorización para operar, al no acordarse su renovación por la oposición de la mayoría del Congreso. La autorización se concedió de nuevo a finales de 2015, pero hasta mayo de 2019 - tras el apoyo del Senado a nuevos miembros del consejo de la entidad- no se obtuvo el quórum necesario para la aprobación de transacciones de más de 10 millones de dólares.

52 Existen grandes diferencias en las estadísticas de crédito a la exportación según las fuentes consultadas (diferente cómputo de periodos, datos no reportados, ruptura de series OCDE con diferencias en el sistema previo de notificaciones de transacciones - recogiendo datos de operaciones con periodo de amortización de un año o superior-).

53 Especialmente en riesgo soberano en el caso de plazos amplios.
}

financiación oficial del comercio internacional a medio y largo plazo en su conjunto (Gráfico 3).

- De una parte, se encuentran las fórmulas tradicionales de financiación oficial al margen del Consenso -financiación de la inversión y financiación concesional desligada-, con una evolución de por sí creciente, y con volúmenes especialmente relevantes en el caso de la financiación de la inversión -con máximos en 2015 y 2016-.

- Por otro lado, cabe destacar la fuerte expansión de la financiación oficial de países no participantes del Consenso. El creciente protagonismo de China ha supuesto una disrupción en el escenario internacional (con un elevado volumen de financiación a la exportación, inversión, desarrollo y otras fórmulas de financiación comercial), provocando cambios en el marco competitivo, dado su elevado grado de flexibilidad, discrecionalidad y opacidad (Horn et al., 2019).

- Asimismo, se está produciendo un creciente recurso a market windows ${ }^{54}$ y programas de financiación desligada, que en el caso de los países signatarios del Consenso supone la posibilidad de desarrollar fórmulas de financiación fuera del ámbito de aplicación del acuerdo.

La financiación de la inversión representa en la actualidad un volumen significativo, con una cifra de 80.000 millones de dólares anuales en promedio en los últimos años —destacando China, seguida de Japón, Corea, Canadá o Alemania (US EXIM Bank, 2002-2020)—. La financiación concesional desligada por $\triangleright$

54 Financiación de entidades a priori privadas y en condiciones de mercado, pero con elevado respaldo institucional. 


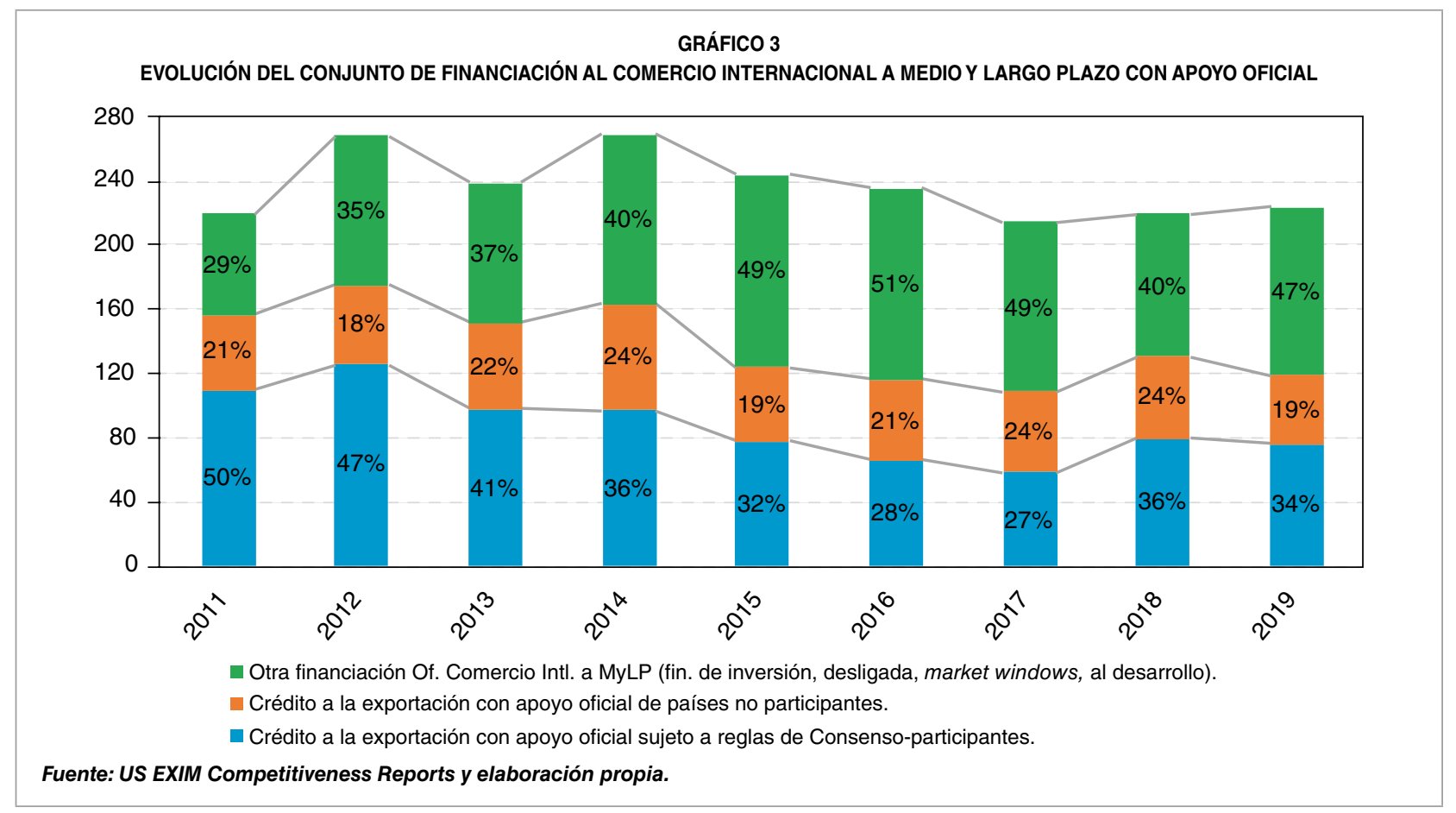

parte de los participantes — sin incluir, por tanto, la concedida por China, también relevante- ha avanzado hasta una media de 15.000 millones de dólares anuales en los últimos años (Gráfico 2), surgiendo de nuevo demandas para su regulación por sus efectos distorsionantes (ausencia de reglas de viabilidad comercial de proyectos y EC mínimo, recelos sobre la difusión de oportunidades y procesos de contratación ${ }^{55}$, sesgos u objetivos más o menos explícitos de instituciones financieras de desarrollo hacia el interés nacional) con una cierta convergencia entre financiación al desarrollo y crédito a la exportación (International Financial Consulting, 2019).

Por su parte, la enorme dimensión y flexibilidad $^{56}$ de la financiación oficial china - estimada conjuntamente en torno a 90.000 millones

55 Más del $25 \%$ de los contratos se adjudica a empresas del país de origen del donante/financiador (con el análisis de la BD OCDE Untied Aid), existiendo ejercicios como 2015 y 2016 en que la cifra ha sido del $65 \%$ (OCDE, 2018b).

56 China no participa de los diferentes compromisos de estándares internacionales o intercambio de información. de dólares (US EXIM Bank, 2019)—, ha supuesto una auténtica disrupción en el comercio internacional y en el escenario geopolítico. Junto con su ECA y EXIM Bank, existen otras entidades gubernamentales, o con apoyo estatal, que ofrecen crédito a la exportación (además de otra financiación relevante desligada o destinada a la inversión).

Asimismo, en un contexto de creciente competencia, existe una mayor innovación, agresividad y flexibilidad por parte de diferentes ECA, con un papel proactivo en la generación de comercio. Algunas han suavizado requisitos de contenido nacional (en favor de un «interés nacional» más amplio), han expandido su red internacional ${ }^{57}$ o complementan el apoyo a ciertos proyectos estratégicos con subvenciones ${ }^{58}$ con un efecto apalancador.

Además, el uso de market windows permite operar fuera de Consenso en $D$

57 Italia, Japón, Corea o Canadá.

58 Países Bajos (Programa DRIVE). 


\section{RECUADRO 1 \\ EL CONSENSO OCDE EN EL CONTEXTO DE LA CRISIS DE LA COVID-19}

Las disciplinas del Consenso OCDE no han sido percibidas en general por los participantes como un obstáculo para el desarrollo de medidas extraordinarias de apoyo financiero oficial, tanto en favor de exportaciones como de las empresas exportadoras, en el contexto de la crisis de la COVID (OCDE, 2020c). Entre las medidas implementadas por una gran parte de países se encuentran:

- Aprobación de líneas extraordinarias de carácter temporal de cobertura de riesgo de crédito circulante -mediante garantías, seguro y reaseguro- concedido a exportadores, para hacer frente a necesidades de liquidez extraordinarias a corto y medio plazo (con vencimiento hasta cinco años, ampliándose posteriormente a ocho años). Se trata de una financiación a exportadores —no sujeta al Consenso, de carácter temporal —en el caso de la UE, al amparo del Marco Temporal de la Comisión relativo a ayudas de Estado para apoyar la economía en el contexto del brote de la COVID-19 (CE, 2020a)-. En todo caso, ha existido diferente capacidad, alcance y términos de los programas entre países -lo que podría ser fuente de distorsiones-.

- Ampliación de fondos disponibles y límites de riesgos - por volumen de transacciones, porcentajes de cobertura o grupos de riesgo OCDE-.

- Oferta de cobertura por cuenta del Estado del riesgo de crédito a corto plazo, incluyendo a países desarrollados —en el caso de la UE, como excepción temporal a la prohibición de cobertura de este tipo de «riesgos comercializables» en circunstancias habituales-.

- Flexibilidades para la reprogramación de calendarios de vencimientos y acuerdos stand-still.

- Moratoria de deuda a los países de renta baja durante 2020, extendiéndose a 2021 —en línea con los del Club de París y el G20 de 2020-.

Por otra parte, si bien la siniestralidad se ha mantenido moderada hasta la fecha, se prevé un repunte a lo largo de 2021, contando en general las ECA con suficiente capacidad al respecto (Unión de Berna, 2020).

Finalmente, en el seno del Grupo de Participantes del Consenso, la UE ha impulsado propuestas de common lines relativas a excepciones temporales respecto de algunas disciplinas (pago anticipado, cálculo del EC), que no obstante no han contado con respaldo unánime para su aprobación. En todo caso, existe la posibilidad de plantear common lines para transacciones individuales, solicitando dispensas justificadas de manera excepcional. 
condiciones de mercado con términos más flexibles ${ }^{59}$. Por otra parte, existe un creciente recurso a financiación comercial desligada ${ }^{60}$, con base en el interés nacional (no sujeta al Consenso), mediante programas pull/push/ shopping lines, no directamente ligados a la firma de contratos de exportación específicos, pero condicionada a la búsqueda de socios comerciales y compromisos futuros (para facilitar a empresas nacionales aprovisionamientos, acceso a compradores relevantes ${ }^{61}$ o participación en cadenas de valor y proyectos de segmentos estratégicos).

Desde 2012 se venía desarrollando una nueva iniciativa de cooperación internacional con el llamado Grupo de Trabajo Internacional de Créditos a la Exportación (International Working Group, o IWG) impulsado por EE UU y con la participación de países participantes y no signatarios del Consenso, con el objetivo de alcanzar un nuevo marco de gobernanza aplicable a todos - proponiéndose un ámbito de aplicación amplio, mecanismos de transparencia y cumplimiento de estándares internacionales-. No obstante, dada la falta de avances y ausencia de compromisos, en noviembre de 2020 se optó por la suspensión temporal de las negociaciones (CE, 2020b).

Finalmente, y coincidiendo con un contexto de tensiones comerciales y reequilibrio de fuerzas globales, la irrupción de la pandemia de la COVID-19 en 2020 ha generado shocks de oferta y demanda, con un notable impacto sobre la economía, exportaciones y empresas (consecuencia de la crisis sanitaria y las medidas de distanciamiento implementadas). En este sentido, se ha producido una cierta

59 Canadá, Alemania o Bélgica.

60 Corea, Japón, Dinamarca, Italia o Reino Unido.

61 Pudiendo partir de la organización de sesiones presenciales B2B entre empresas nacionales y extranjeras. readaptación del apoyo financiero oficial para hacer frente a tales efectos (Recuadro 1).

\section{Desafíos actuales y modernización del Consenso}

En la actualidad, y como consecuencia de la transformación del escenario internacional, el Consenso ha visto reducido su grado de influencia y representatividad, en detrimento del level playing field, con una creciente convergencia y competencia entre fuentes de financiación oficial.

Asimismo, con la modernización de la ayuda oficial al desarrollo, los países impulsan el uso de instrumentos financieros a través de agencias, instituciones y bancos de desarrollo, carentes de una regulación en común con las ECA, sin mecanismos que impidan potenciales efectos distorsionantes (Søndergaard, 2019).

Existe además, como apunta Klasen (2017), una situación de bloqueo en el régimen comercial internacional, con la práctica imposibilidad de alcanzar consensos en la OMC, una pluralización de acuerdos comerciales que no ha aportado necesariamente mayor coherencia y una creciente multipolaridad que podría dificultar los avances y ser un factor de bloqueo, surgiendo la cuestión de si serán necesarias transformaciones profundas del sistema para superar el bloqueo y evitar mayores deterioros.

En un contexto de polarización y fragmentación, la competencia y la generalización de un comportamiento agresivo no reglado por parte de las ECA, dentro y fuera de la OCDE, podrían incrementar tensiones y generar una carrera a la baja con efectos negativos sobre el comercio internacional. 
Desde los años ochenta, el progresivo desarrollo de reglas del Consenso sobre financiación oficial —sujeta a compromisos medioambientales, sociales y éticos- permitió sentar las bases de un sistema sólido y predecible durante más de treinta años. No obstante, como expresa Laurent (2015), frente a esa «era de claridad», la transformación del escenario estaría dando paso en la actualidad a una «era de incertidumbre» que podría extenderse en el tiempo.

De otra parte, la ausencia de incentivos para un mayor compromiso de China en disciplinas internacionales presagiaba una senda complicada para el IWG. La constatación de la falta de avances sustanciales tras ocho años de negociación supone un cierto fracaso plasmado en la suspensión temporal de las negociaciones para las deseables reglas multilaterales. No obstante, también existen pequeños avances en algunas áreas respecto de mejora de prácticas en el país asiático, a partir de iniciativas de coordinación bilateral ${ }^{62}$, regional y participación en diferentes foros por parte de China o sus ECA (caso de la UB), siendo aconsejable retomar próximas oportunidades para su atracción hacia un marco de gobernanza internacional.

\section{Modernización del Consenso}

Por otro lado, el proceso recientemente lanzado entre los participantes para la completa modernización del Consenso pretende facilitar una revisión integral del texto para su actualización frente a la realidad actual, en línea con demandas internas y del sector empresarial (BIAC, 2019). La modernización debería tener

\footnotetext{
62 Caso del Acuerdo sobre Inversiones (CIA) entre la UE y China (con un principio de acuerdo en diciembre de 2020).
}

un enfoque ambicioso, que podría comprender el desarrollo de disciplinas relativas a financiación a tipos de interés variable; el desarrollo de un «enfoque holístico» en la revisión del conjunto de términos financieros, con la propuesta de introducción de flexibilidades a cambio de su reflejo en prima (Rijksoverheid, 2020) - con un trade off entre claridad (por la comparabilidad de reglas homogéneas ortodoxas) y flexibilidad (a través de límites no rígidos)—; revisión del mecanismo de matching; profundización respecto de compromisos de sostenibilidad ambiental con un enfoque transversal $^{63}$ y coherente con otras fuentes de financiación internacional (Shishlov et al., 2020).

Asimismo, la modernización incluye compromisos de revisión de áreas no incluidas en el ámbito de aplicación del Consenso respecto de su potencial efecto distorsionante, siendo deseable voluntad política y apoyo a favor de extender reglas y mecanismos de transparencia y supervisión a nuevos ámbitos (con una mayor imbricación entre financiación al comercio ligada/desligada, inversión o desarrollo, además de su colaboración con el sector privado). Para ello, resultaría aconsejable dotarse de un marco de supervisión honesto de las diferentes prácticas y programas de las ECA para una adecuada transparencia.

\section{Conclusiones}

Tras 45 años de historia, el Consenso ha favorecido un amplio periodo de estabilidad y coordinación, reduciendo subvenciones y disputas comerciales, con un continuo proceso $D$

\footnotetext{
63 Más allá del actual proceso de revisión del CCSU y del CFSU.
} 
de actualización y adaptación al entorno económico y demandas sociales, sentando las bases para el impulso de las mejores prácticas internacionales.

La expansión de prácticas proactivas y agresivas por parte diferentes ECA en apoyo del «interés nacional» son una reacción frente a los cambios en el panorama internacional. Los participantes más conservadores y respetuosos del modelo tradicional defienden la actualización de un marco multilateral mejorado que salvaguarde el level playing field, pero se ven a su vez apremiados ante la posibilidad de desarrollar programas fuera del Consenso para preservar su capacidad competitiva. En todo caso, la generalización de tales prácticas podría redundar en una carrera a la baja, con un creciente riesgo de tensiones y guerra comercial.

La modernización del Consenso es un ejercicio necesario no exento de dificultad, pero, en cualquier caso, la solución definitiva debería venir de la mano de un verdadero acuerdo multilateral —no necesariamente en el ámbito de la OCDE- y con vocación global respecto a las áreas cubiertas, países y sectores.

A diferencia de los años setenta -en que los actores relevantes formaban un grupo pequeño y homogéneo, con un interés común y un liderazgo claro-, cincuenta años después, el contexto multipolar actual añade complejidad.

Frente al nuevo periodo de mayor incertidumbre -que podría extenderse en el tiempo-, es deseable voluntad política, altura y visión a largo plazo de los Gobiernos, para constatar los efectos de la ausencia de un marco común, impulsando y aprovechando futuras iniciativas de coordinación, atrayendo a los diferentes actores hacia un marco de gobernanza global, sólido y sostenible.

\section{Bibliografía}

BIAC (2019). Joint Business Position on the Modernization of the OECD Arrangement: Ensuring a global level playing field. https://biac.org/ wp-content/uploads/2019/11/Final-version-Jointbusiness-position-on-Future-of-OECD-Arrangement5.pdf

CE (1997). Communication of the Commission [...] on Short Term Export Credit Insurance. 1997/C/281/03, 17/09/1997. https://eur-lex.europa.eu/legal-content/EN/ALL/?uri=CELEX \% 3A31997Y0917\%2801\%29

CE (2020). Communication of the Commission on the Temporary Framework for State aid measures to support the economy in the current COVID-19 outbreak, European Commission. C/2020/1863, 19/03/2020. https://ec.europa.eu/ competition/state_aid/what_is_new/covid_19. html

CE (19 November, 2020). EU and 10 other members suspend participation in negotiations in the International Working Group on Export credits. European Comission, Press Release. https://trade.ec.europa.eu/doclib/press/index.cfm?id= 2214

Dawar, K. (2020). Official export credit support: competition and compliance issues. Journal of World Trade, 54(3), 373-395. http://respect.eui.eu/ wp-content/uploads/sites/6/2019/08/Dawar 2019_JWT_pre_publication.pdf

Horn, S., Reinhart, C., \& Trebesch, C. (2019). China's Overseas Lending. NBER Working Papers 26050, National Bureau of Economic Research. https://www.nber.org/system/files/working_papers/w26050/w26050.pdf

International Financial Consulting (2019). Study on convergence of Development Finance and Export Finance. https://tem.fi/documents/1410877/ 17666274/International+Financial+Consulting/4 141109e-5531-406a-f1de-69617c26c744/International+Financial+Consulting.pdf

Klasen, A. (2017). Trade: Gridlock and resilience. In T. Hale \& D. Held (eds.), Beyond Gridlock (pp. 65-82). Polity. 
Kuhn, M.G., Horváth, B., \& Jarvis, C.J. (1995). Officially Supported Export Credit. Recent Developments and Prospects. World Economic \& Financial Series, International Monetary Fund. https:// www.elibrary.imf.org/doc/l M F 083 / 05004-9781557754486/05004-9781557754486/ Other_formats/Source_PDF/050049781455257676.pdf

Laurent, X. (2015). The Future of Foreign Trade Support: The Era of Uncertainty. In A. Klasen and F. Bannert (eds.), The Future of Foreign trade support: Setting global Standards for Export Credit and Political Risk Insurance (pp. 69-73). Global Policy.

Levit, J.K. (2004). The Dynamics of International Trade Finance regulation: The Arrangement on Officially Supported Export Credits. Harvard International Law Journal, 45(1), 65-182. https:// core.ac.uk/download/pdf/232685608.pdf

Moravcsik, A.M. (1989). Disciplining Trade Finance: The OECD Export Credit Arrangement. International Organization, Cambridge University Press, 43(1), 173-205. https://www.princeton.edu/ amoravcs/library/oecd.pdf

OCDE (2005). Agreement on Untied ODA Credits transparency. TD/PG/2005/8. https://one.oecd. org/document/TD/PG(2005)8/en/pdf

OCDE (2016). OECD Recommendation of the Council on Common Approaches for Officially Supported Export Credits and Environmental and Social Due Diligence. TAD/ECG/2016/3. http://www.oecd.org/officialdocuments/publicdisplaydocumentpdf $/$ doclanguage $=$ en $\&$ cote $=$ tad $/$ ecg(2016)3

OCDE (2018). Recommendation of the Council on Sustainable Lending Practices and Officially Supported Export Credits. OECD/LEGAL/0442. https://legalinstruments.oecd.org/public/ doc/637/637.en.pdf

OCDE (2018). Report on the DAC Untying Recommendation. DCD/DAC/2018/12/REV2. https:// www.oecd.org/dac/financing-sustainable-development/development-finance-standards/DCDDAC(2018)12-REV2.en.pdf
OCDE (2018). DAC Recommendation on Untying Official Development Assistance, OECD/LEGAL/5015. https://legalinstruments.oecd.org/public/doc/140/140.en.pdf

OCDE (2019). Recommendation of the Council on Bribery and Officially Supported Export Credits. OECD/LEGAL/0447. http://www.oecd.org/officialdocuments/publicdisplaydocumentpdf/?cote=$\mathrm{TAD} / \mathrm{ECG}(2019) 2 \&$ docLanguage $=\mathrm{En}$

OCDE (2020). Arrangement on Officially Supported Export Credits. TAD/PG/2020/1. http://www.oecd. org/officialdocuments/publicdisplaydocumentpd$\mathrm{f} /$ ?doclanguage $=e n \&$ cote $=\operatorname{tad} / \mathrm{pg}(2020) 1$

OCDE (2020). Evolution of the Arrangement on Officially Supported Export Credits. TAD/PG/2020/1. http://www.oecd.org/officialdocuments/publicdisplaydocumentpdf $/$ ?cote $=\operatorname{tad} / p g(2020) 2 \&$ doclanguage $=e n$

OCDE (2020). Summary of the Responses to the Survey on Export Credits and The Coronavirus (COVID-19) Pandemic. TAD/EC/2020/10. http:// www.oecd.org/officialdocuments/publicdisplaydocumentpdf $/$ ?doclanguage $=$ en $\&$ cote $=T A D /$ ECG(2020) 10

Reglamento (UE) 1233/2011 del Parlamento Europeo y del Consejo relativo a la aplicación de determinadas directrices en materia de créditos a la exportación con apoyo oficial. DOUE de 8 de diciembre de 2011. https://www.boe.es/ doue/2011/326/L00045-00112.pdf

Rijksoverheid (2020). Monitor exportkredietverzekeringen 2019. Documento parlamentario Países Bajos, 2 de octubre de 2020. https://www.rijksoverheid.nl/documenten/kamerstukken/2020/10/02/ monitor-exportkredietverzekeringen-2019

Rosefsky, K.P. (1993). Tied aid Credits and the New OECD Agreement. University of Pennsylvania. J. Intl Law (437). https://scholarship.law.upenn. edu/cgi/viewcontent.cgi?article $=1533 \&$ context $=$ jil

Shishlov, I., et al. (2020). External and Internal Climate Change Policies for Export Credit and Insurance Agencies. CIS Working Paper (104). $D$ 


\section{EL CONSENSO DE LA OCDE SOBRE CRÉDITOS A LA EXPORTACIÓN CON APOYO OFICIAL...}

https://ethz.ch/content/dam/ethz/special-interest/ gess/cis/cis-dam/CIS_2020/Working \%20paper\%20Axel.pdf

Søndergaard-Jensen, M. (2019). Will OECD Governments avoid the Path Towards a New Credit War? Global Policiy, 10(3). 427-431. https://onlinelibrary.wiley.com/doi/full/10.1111/1758-5899. 12726

Unión de Berna (2020). Yearbook 2020. https:// www.berneunion.org/Publications

US EXIM Bank (2002-2020). US EXIM Competitiveness Reports. 2001-2019 Reports to the Congress on Global Export Credit Competition. https://www.exim.gov/news/reports/competitivenessreports

Vía Ozalla, O., García Grande, E., y Zaballa Gómez, J.J. (1993). El Crédito a la Exportación con Apoyo Oficial: Marco general actual e instrumentos. Información Comercial Española, Revista de economía (718), 11-24.

Wang, J. Y. et al. (2005). Officially Supported Export Credits in a Changing World. World Economic and Financial Surveys, International Monetary Fund. https://www.elibrary.imf.org/doc/IMF083/ 05003-9781589064355/05003-9781589064355/ Other_formats/Source_PDF/050039781451924152.pdf 
